\section{EFFECT OF ION IMPLANTATION ON THE CORROSION BEHAVIOR OF LEAD AND LEAD-ANTIMONY ALLOY}

\author{
R. H. Muller and S.-T. Zhang \\ Materials Sciences Division \\ Lawrence Berkeley Laboratory \\ University of California \\ Berkeley, CA. 94720
}

Grid corrosion, particularly in the positive plate, is an important factor that limits the cycle life of leadacid batteries. It has received considerable attention [1, 2].

In the present work, surface modification by ion implantation has been investigated to reduce the corrosion of grid materials. Titanium was primarily used for implantation; pure lead $(99.99 \%)$ and a lead$4 \%$ antimony alloy were chosen as representative grid materials. The implantation of several other elements produced similar results. Ion implantation has been used before to modify surface properties of metals such as hardness and corrosion resistance $[3,4]$.

The ion implantation was performed with a new high-current, pulsed ion source that has been described elsewhere [5]. The purity of the $\mathrm{Ti}$ arc source was $99.999 \%$. Typical beam current densities were 2.55 $\mathrm{mA} / \mathrm{cm}^{2}$, typical pulse durations $0.24 \mathrm{~ms}$, and pulse frequencies $5-10 \mathrm{~Hz}$. Ion beam energies of $30-120 \mathrm{keV}$, and implantation doses of $1 \times 10^{15}$ to $5 \times 10^{17}$ atoms $/ \mathrm{cm}^{2}$ were used.

Two methods were employed io determine the corrosion behavior of the grid materials: Corrosion rates were derived from the current response of the specimens in $5 \mathrm{M} \mathrm{H}_{2} \mathrm{SO}_{4}$ to small anodic polarization (3$10 \mathrm{mV}$ ), extrapolated from short-term measurements to zero time (in order to represent the behavior of the original surface). Also, the morphology of the corroded surface after extended $(60 \mathrm{~h})$ open circuit immersion in the sulfuric acid was determined by SEM.

The dependence of corrosion currents for lead and lead-4\% antimony on titanium ion ciose and energy is illustrated in Figs. 1 and 2. Optimum implantation conditions are slightly different for the two specimens but lie in the vicinity of $5 \times 10^{16}$ atoms $/ \mathrm{cm}^{2}$ and $60 \mathrm{keV}$. Compared to the untreated specimens, corrosion currents are reduced by the ion implantation up to 36 . fold for the pure lead and up to 72 -fold for the lead. antimony alloy.

The effect of the implantation of some other ions on corrosion currents is comparable to that of titanium and is illustrated in Table 1 for one set of implantation conditions.

Depth profiles of the implarted lons, obtained by Auger spectroscopy, are shown in Fig. 3. These profiles compare well with computed profiles and, together witn anodic and cathodic polarization measurements, provide mechanistic information on the effect of ion implantation

\section{REFERENCES:}

[1] V. Daniel and V. Plichon, Electrochim. Acta 20,781 (1983).

[2] Y.-L. Guo, J. Electrochem. Soc. 138, 1222

[3] I.G. Brown, M.R. Dickinson, J.E. Galvin, X. Godechot and R.A. MacGill, J. Materials Eng., 13, 217 (1991).

[4] D. Gorse, B. Rondot and Y. Serruys, Corros. Sci..31, 685, (1990).

[5] I.G. Brown, M.R. Dickinson, J.E. Galvin, X. Godechot and R.A. MacGill, 7th International Conference on Surface Modification of Metals by Ion Beams, Washington, DC, July' 15-19,1991.

\section{ACKNOWLEDGMENTS}

We thank I. G. Brown fot his help with the use of the ion implantation equipment.

This work was supported by the Assistant Secretary for Conservation and Renewable Eriergy, Office of Transportation Technologies, Electric and Hybrid Propulsion Division of the U.S. Department of Energy under Contract No. DF.AC03-76SF00098. 
Table 1. Effect of the ion implantation of different atoms on the corrosion of lead and lead-4\% antimony alloy in 5 molar sulfuric acid.

\begin{tabular}{|c|c|c|c|c|c|c|c|}
\hline \multicolumn{6}{|c|}{ Implantation Conditions } & \multicolumn{2}{|c|}{$\begin{array}{l}\text { Corrotion } \\
\text { Current }\end{array}$} \\
\hline \multirow[t]{2}{*}{ Ion } & $\begin{array}{l}\text { En- } \\
\text { er- } \\
\text { gy }\end{array}$ & $\begin{array}{l}\text { Dose } \\
\text { atoms }\end{array}$ & $\begin{array}{l}\text { Peak } \\
\text { Current } \\
\text { Density }\end{array}$ & $\begin{array}{l}\text { Pulse } \\
\text { Dura. } \\
\text { tion }\end{array}$ & $\begin{array}{c}\text { Pulse } \\
\text { Frequen. } \\
\text { cy }\end{array}$ & $\mathrm{mA}$ & $1 \mathrm{~cm}^{2}$ \\
\hline & $\mathrm{keV}$ & $1 \mathrm{~cm}^{2}$ & $\mathrm{~mA} / \mathrm{cm}^{2}$ & $\mathrm{~m} \approx$ & $\mathrm{Hz}$ & $\overline{\mathrm{F}}$ & $\begin{array}{l}\mathrm{Pb} \cdot \\
4 \% \mathrm{Sb}\end{array}$ \\
\hline $\mathrm{Ti}$ & 60 & $5 \times 10^{16}$ & 2.65 & 0.24 & 5 & 0.15 & 0.040 \\
\hline $\bar{\nabla}$ & 60 & $5 \times 11^{16}$ & 2.55 & 0.2 .4 & 10 & 0.20 & 0.053 \\
\hline $\mathrm{Cr}$ & 60 & $5 \times 10^{16}$ & 2.55 & 0.24 & 10 & 0.27 & 0.093 \\
\hline$\overline{\mathrm{Ni}}$ & 60 & $5 \times 10^{16}$ & 2.56 & 0.24 & 10 & 0.18 & $0.08 \bar{J}$ \\
\hline $\bar{W}$ & 180 & $5 \times 10^{16}$ & 2.65 & 0.24 & -3 & 0.81 & 0.51 \\
\hline $\begin{array}{l}\text { no. } \\
\text { ne }\end{array}$ & . & 0 & $\cdot$ & $\cdot$ & $\cdot$ & 5.4 & 2.9 \\
\hline
\end{tabular}

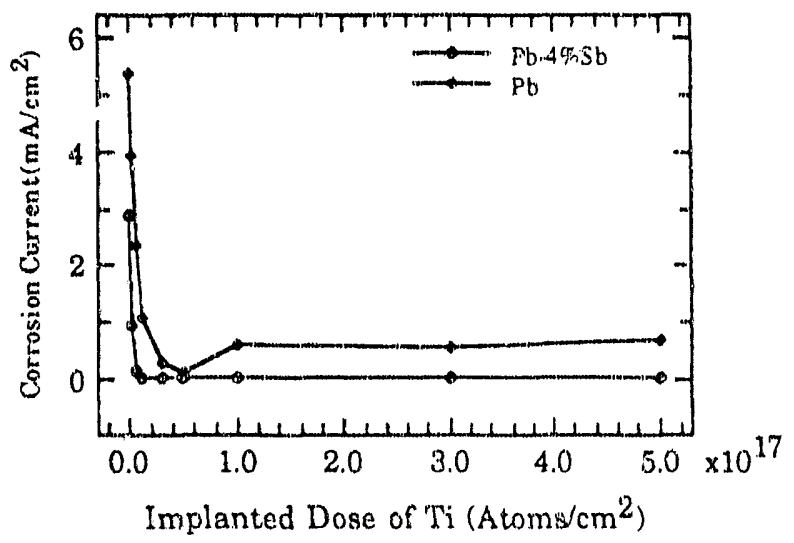

Fig.1 Dependence of corrosion current of $\mathrm{Pb}$ and $\mathrm{Pb}-\mathrm{Sb}$ on dose of Ti implantation conducted at $60 \mathrm{keV}$.

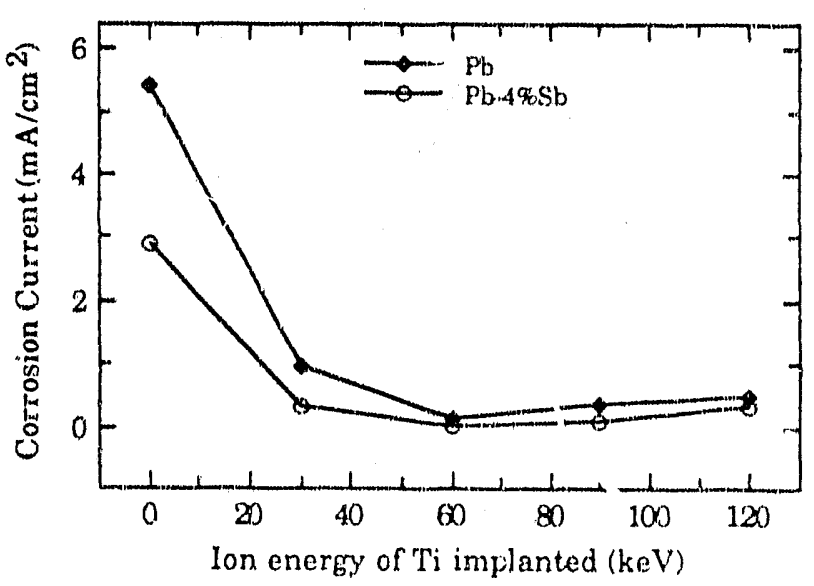

Fig.2 Dependence of corrosion current of $\mathrm{Pb}$ and $\mathrm{Pb}-\mathrm{Sb}$ on $\mathrm{Ti}$ ion energy of implantation at $5 \times 10^{16}$ atorns $/ \mathrm{cm}^{2}$.

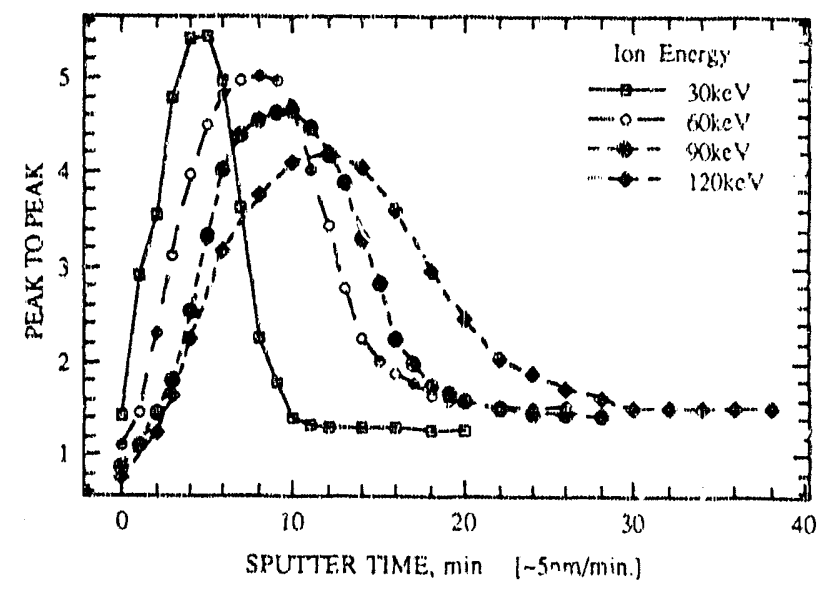

Fig. 3 Measured depth profiles of $\mathrm{Ti}$ distribution in $\mathrm{Pb}$ for different implantation energies and a dose of $5 \times 10^{16}$ atorns $/ \mathrm{cm}^{2}$ 
